\title{
Neutrophil-to-Lymphocyte Ratio and Platelet Count Predict Long-Term Outcome of Stage IIIC Epithelial Ovarian Cancer
}

\author{
Mingyi Zhou Liankun Li Xiaobin Wang Chunyan Wang Danbo Wang \\ Department of Gynecology, Cancer Hospital of China Medical University, Liaoning Cancer Hospital \& \\ Institute, Shenyang, Liaoning Province, PR China
}

\section{Key Words}

Epithelial ovarian cancer - Neutrophil-to-lymphocyte ratio Platelet count Progression-free survival $\cdot$ Overall survival

\begin{abstract}
Background/Aims: Prognostic value of neutrophil-to-lymphocyte ratio (NLR) and platelet count (PC) in patients with International Federation of Gynecology and Obstetrics (FIGO) stage IIIC epithelial ovarian cancer (EOC) is controversial. Methods: A total of 370 stage IIIC EOC patients who underwent primary debulking surgery (PDS) at the Department of Gynecology of Liaoning Cancer Hospital and Institute between January 2003 and August 2016 and had full information were involved. Patients were stratified into a high NLR (H-NLR) group versus a low NLR (L-NLR) group and a high PC (H-PC) group versus a low PC (L-PC) group according to cutoff values calculated through receiver operating characteristic (ROC) curves. Prognostic values of NLR and PC for progression-free survival (PFS) and overall survival (OS) were assessed. Results: We identified the optimal cut-off value of 3.08 for NLR and $289.5^{*} 10^{9} / \mathrm{L}$ for PC. The median PFS and OS of the patients with H-NLR were shorter than L-NLR (PFS: 16.9 months vs. 19.5 months, hazard ratio [HR] 1.3, 95\% confidence interval [CI] 1.03-1.63, $P=0.022$; OS: 33.5 months vs. 46.8 months, HR 1.3, 95\% CI 1.01-1.66, $P=0.001$ ). The median PFS and OS of the patients with $\mathrm{H}-\mathrm{PC}$ were shorter than L-PC (PFS: 15.3 months vs. 21.6 months, HR 1.3, 95\% CI $1.04-1.63, P<0.001$; OS: 37.3 months vs. 46.1 months, HR 1.14, 95\% CI 0.89-1.46, $P=0.306$ ). Conclusions: $\mathrm{H}-\mathrm{NLR}$ and $\mathrm{H}-\mathrm{PC}$ could predict poor long-term outcome of patients with FIGO stage III EOC.

\section{Introduction}

Epithelial ovarian cancer (EOC) has a poor prognosis. There were 22, 440 estimated new cases and 14, 080 deaths in the United States in 2017 [1] and 52, 100 estimated new cases and 22, 500 deaths in China in 2015 [2]. Even though optimal primary debulking surgery (PDS) and carboplatin-based chemotherapy have improved survival, the 5-year

Danbo Wang,

Chunyan Wang

and Xiaobin Wang
Department of Gynecology, Cancer Hospital of China Medical University,

Liaoning Cancer Hospital \& Institute (PR China)

E-Mail wangdanbo@cancerhosp-In-cmu.com, wangchunyan@cancerhosp-In-cmu.com, 
overall survival rate of FIGO stage III ovarian cancer (OC) is 24.26\% [3]. Specific and effective biomarkers for predicting the treatment outcome of advanced EOC are urgently needed.

Tumor-associated neutrophils and thrombocytosis have been demonstrated to play important roles in tumor progression, angiogenesis, and invasion of EOC [4]. Increased neutrophil to lymphocyte ratio (NLR) and platelet count (PC) are associated with the disease severity and poor prognosis of several kinds of malignant tumor [5-8]. Two meta-analyses about the prognostic significance of neutrophil to lymphocyte ratio in ovarian cancer were published in 2017[9, 10]. The results showed the high NLR (H-NLR) were associated with unfavorable overall survival (OS) and progression-free survival (PFS). But extreme heterogeneity existed among studies (heterogeneity of OS: $I^{2} 80.2 \%, P<0.001$; heterogeneity of PFS: $I^{2} 85.2 \%, P<0.001$ ). The subgroup analyses of both two meta-analyses according to ethnicity showed that H-NLR was associated with shorter OS for Asian patients but not Caucasian patients. Furthermore, difference of incidence and mortality of cancer existed between the patients in North and South China [2]. And the characteristics of ovarian cancer patients between North and South China were not consistent [11]. In Chen's meta-analysis, there were five Chinese studies and all of them were sponsored by the institutes in South China. In Zhou's meta-analysis, there were six Chinese studies. Among these six studies, five studies were sponsored by the institutes in South China. Only one study was sponsored by an institute in North China. And only 80 patients with FIGO stage III-IV ovarian cancer were included this retrospective study [12]. So the correlation between NLR and the prognosis of FIGO stage IIIC EOC patients in Northeast China needed further investigation.

\section{Materials and Methods}

\section{Clinical Data}

This retrospective study was approved by the ethics committees of Liaoning Cancer Hospital and Institute (Cancer Hospital of China Medical University). Written informed consent was obtained from each patient included in this study.

A total of 370 patients with FIGO stage IIIC EOC who underwent primary debulking surgery (PDS) were retrospectively investigated between January 2003 and August 2016 at the Department of Gynecology of Liaoning Cancer Hospital and Institute. All enrolled patients met the following criteria: (1) diagnosis of FIGO stage IIIC EOC; (2) performance of PDS without neoadjuvant chemotherapy; (3) suspicion of intra-abdominal diffuse disease based on preoperative radiological assessments (computed tomography/ ultrasonography); (4) use of platinum-based chemotherapy as postoperative adjuvant chemotherapy; (5) availability of data including neutrophil count, lymphocyte count, and PC; and (6) availability of other data including age, preoperative serum CA125 concentration, volume of ascites, histology and grade of tumor, Gynecologic Oncology Group performance status, and maximum size of residual disease. The 2014 FIGO guidelines removed patients with only positive retroperitoneal lymph nodes from the definition of stage IIIC EOC[13]. Therefore, we reassessed the cancer stage for all patients before 2014 according to their pathological reports. NCCN guideline was followed during the diagnosis and treatment of patients. All patients were followed up until April 30, 2017.

Optimal PDS was defined as residual disease (RD) $\leq 1 \mathrm{~cm}$, and suboptimal PDS was defined as RD $>1 \mathrm{~cm}$. PFS was defined as the time interval from the date of PDS to the date of disease progression or recurrence. OS was defined as the time interval from the date of PDS to the date of death or the last follow-up.

NLR was defined as neutrophil count divided by lymphocyte count. PC was defined as the absolute value of platelet count. Preoperative peripheral blood samples from the patient were drawn within 5 days prior to surgery.

\section{Statistical Analyses}

The optimal cut-off values of NLR and PC for predicting OS were calculated through receiver operating characteristic (ROC) curves. A total of 370 patients were stratified as H-NLR group versus low NLR (L-NLR) group and as high PC (H-PC) group versus low PC (L-PC) group according to cut-off values. H-NLR and H-PC were each assigned a score of 1 , and peripheral blood index value (PBIV) was defined as the total score 
according to the status of NLR and PC. The optimal cut-off value of PBIV predicting OS was calculated through ROC curves.

The categorical data were compared with chi-square tests. PFS and OS were analyzed using the Kaplan-Meier method. Univariate analyses were performed using log-rank tests. Multivariate analyses were performed using Cox regression analysis to assess the effects of the prognostic factors, which were expressed as hazard ratios. $P<0.05$ was considered statistically significant, and all $P$ values were two-sided. Some factors, such as pre-operative ascites volume, belonged to multiple categorical variables. When $<1000 \mathrm{ml}$ group was considered as the reference group, two dummy variables associated with 1000-3000ml and $>3000 \mathrm{ml}$ groups, respectively, were included in the COX model. Hence, the hazard ratios were estimated between the pairs of the groups [14]. All data analyses were performed using SPSS 16.0 (SPSS Inc., Chicago, IL).

\section{Results}

Cut-off values of NLR and PC

A total of 370 patients with stage FIGO III EOC were finally included in our retrospective study according to the inclusion criteria. Table 1 shows the characteristics of the patients. In 238 patients with serous carcinoma, 16 patients had low grade serous carcinoma and the other 222 patients had high grade serous carcinoma.

The following optimal cut-off values were identified: 3.08 for NLR (area under curve [AUC] $0.66, P<0.001$, sensitivity 0.62 , specificity 0.65 ) and $289.5^{*} 10^{9} /$ L for PC (AUC $0.61, P$ $<0.001$, sensitivity 0.52 , specificity 0.67 ) (Fig. 1). Therefore, H-NLR referred to patients with NLR $>3.08$ and H-PC referred to patients with PC $>289.5^{*} 10^{9} / \mathrm{L}$.

\section{Correlation between NLR and PC and clinicopathological variables}

The associations between NLR and PC and the main clinicopathological variables of patients with FIGO stage IIIC EOC were investigated (Table 2). H-NLR was observed more often in younger patients $(P=0.034)$, patients with more preoperative ascites $(P<0.001)$, higher preoperative CA125 value $(P=0.004)$, lower differentiation of tumor $(P=0.009)$, longer period of stay in hospital $(P=0.012)$, patients had blood transfusion $(P=0.001)$, and patients had plasma transfusion $(P<0.001)$. H-PC was more often observed in patients with more preoperative ascites $(P<0.001)$ and those with higher preoperative CA125 value $(P=0.001)$.

\section{NLR and PC and survival analysis}

PFS and OS according to the main clinicopathological variables, NLR, and PC are shown in Table 3.

Regarding PFS, from univariate analysis the variables associated with a shorter PFS included menopause status, volume of preoperative ascites, histology of tumor, grade of tumor, 


\section{Cellular Physiology Cell Physiol Biochem 2018;46:178-186

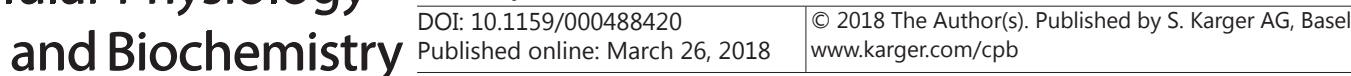 \\ Zhou et al.: NLR and PC Predict the Outcome of IIIC EOC}

stay in hospital, RD, regimen of adjuvant chemotherapy, second debulking surgery, NLR, and PC. Furthermore, from multivariate analysis by Cox regression the independent variables associated with a shorter PFS were histology of tumor, grade of tumor, RD, NLR, and PC. Patients with serous carcinoma mucinous had shorter PFS than endometriod carcinoma but longer PFS than mucinous carcinoma. Patients with poor differentiation of tumor, RD $>1 \mathrm{~cm}, \mathrm{NLR}>3.08$, and $\mathrm{PC}>289.5^{*} 10^{9} / \mathrm{L}$ had shorter PFS and were more likely to relapse after the initial treatment. The median PFS of patients with NLR $>3.08$ was 2.6 months shorter than that of patients with NLR $<3.08$ (16.9 months vs. 19.5 months, HR $1.3,95 \%$ CI 1.03-1.63, $P=0.022$ ). The median PFS of patients with PC $>289.5^{*} 10^{9} / \mathrm{L}$ was 6.3 months shorter than that of patients with PC $<289.5^{*} 10^{9} / \mathrm{L}(15.3$ months vs. 21.6 months, HR 1.3, 95\% CI 1.04-1.63, $P<0.001$ ) (Fig. 2 and Table 3).

Regarding OS, from univariate analysis the variables associated with a shorter OS included histology of tumor, grade of tumor, RD, blood transfusion, regimen and cycles of adjuvant chemotherapy, second debulking surgery, NLR, and PC. Multivariate analysis by Cox regression showed that the independent variables associated with a shorter OS were histology of tumor, grade of tumor, RD, cycle of adjuvant chemotherapy and NLR. Patients with serous carcinoma mucinous had shorter OS than endometriod carcinoma but longer OS than mucinous carcinoma. Patients with $\geq 6$ cycles of adjuvant chemotherapy had longer OS that $<6$ cycles. Patients with poor differentiation of tumor, RD $>1 \mathrm{~cm}$, and NLR $>3.08$ had shorter OS. The median OS of patients with NLR >3.08 was 13.3 months shorter
Fig. 1. ROC curves of NLR (A) and $\mathrm{PC}(\mathrm{B})$ as predictors of OS.
Table 2. Correlations between NLR and PC and main clinicopathological variables for the patients. *Grade 1 referred to the well-differentiated epithelial ovarian cancer; Grade 2 referred to the moderately-differentiated epithelial ovarian cancer; Grade 3 referred to the poorly-differentiated epithelial ovarian cancer. Abbreviations: NLR, neutrophil-to-lymphocyte ratio; PC, platelet count; RD, residual disease; PDS, primary debulking surgery

\begin{tabular}{|c|c|c|c|c|c|c|c|}
\hline & No. of patients & H-NLR & L-NLR & $\begin{array}{l}\text { Pof NLR } \\
\end{array}$ & H-PC & L-PC & P of PC \\
\hline Age (y) & & & & 0.034 & & & \\
\hline$<65$ & 315 & $169(53.7 \%)$ & $146(46.3 \%)$ & & $184(58.4 \%)$ & $131(41.6 \%)$ & \\
\hline$\geq 65$ & 55 & $21(38.2 \%)$ & $34(61.8 \%)$ & & $28(50.9 \%)$ & $27(49.1 \%)$ & \\
\hline Menopause & & & & 0.908 & & & 0.055 \\
\hline No & 145 & $75(51.7 \%)$ & $70(48.3 \%)$ & & $92(63.4 \%)$ & $53(36.6 \%)$ & \\
\hline Yes & 225 & $115(51.1 \%)$ & $110(48.9 \%)$ & & $120(53.3 \%)$ & $105(46.7 \%)$ & \\
\hline Pre-operative ascites volume (ml) & & & & $<0.001$ & & & $<0.001$ \\
\hline$<1000$ & 153 & $55(35.9 \%)$ & $98(64.1 \%)$ & & $64(41.8 \%)$ & $89(58.2 \%)$ & \\
\hline $1000-3000$ & 127 & $77(60.6 \%)$ & $50(39.4 \%)$ & & $79(62.2 \%)$ & $48(37.8 \%)$ & \\
\hline$>3000$ & 90 & $58(64.4 \%)$ & $32(35.6 \%)$ & & $69(76.7 \%)$ & $21(23.3 \%)$ & \\
\hline Pre-operative CA125 value & & & & 0.004 & & & 0.001 \\
\hline$<1000$ & 269 & $124(46.1 \%)$ & $145(53.9 \%)$ & & $141(52.4 \%)$ & $128(47.6 \%)$ & \\
\hline $1000-5000$ & 86 & $57(66.3 \%)$ & $29(33.7 \%)$ & & $57(66.3 \%)$ & $29(33.7 \%)$ & \\
\hline$>5000$ & 15 & $9(60 \%)$ & $6(40 \%)$ & & $14(93.3 \%)$ & $1(6.7 \%)$ & \\
\hline Histology of tumor & & & & 0.835 & & & 0.061 \\
\hline Serous & 238 & $123(51.7 \%)$ & $115(48.3 \%)$ & & $145(60.9 \%)$ & $93(39.1 \%)$ & \\
\hline Endometriod & 46 & $23(50 \%)$ & $23(50 \%)$ & & $24(52.2 \%)$ & $22(47.8 \%)$ & \\
\hline Mucinous & $\frac{40}{3}$ & $2(66.7 \%)$ & $1(33.3 \%)$ & & $1(33.3 \%)$ & $2(66.7 \%)$ & \\
\hline Clear cell & 4 & $3(0.8 \%)$ & $1(49.4 \%)$ & & $2(50.0 \%)$ & $2(50.0 \%)$ & \\
\hline Adenocarcinoma, not otherwise & 79 & $39(49.4 \%)$ & $40(50.6 \%)$ & & $40(50.6 \%)$ & $39(49.4 \%)$ & \\
\hline $\begin{array}{l}\text { specified } \\
\text { Grade of tumor }\end{array}$ & & & & 0.009 & & & 0.733 \\
\hline G1 & 24 & $10(41.7 \%)$ & $14(58.3 \%)$ & & $12(50 \%)$ & $12(50 \%)$ & \\
\hline $\mathrm{G} 2$ & 133 & $56(42.1 \%)$ & $77(57.9 \%)$ & & $78(58.6 \%)$ & $55(41.4 \%)$ & \\
\hline G3 & 213 & $124(58.2 \%)$ & $89(41.8 \%)$ & & $122(57.3 \%)$ & $91(42.7 \%)$ & \\
\hline Stay in hospital (d) & & & & 0.012 & & & 0.517 \\
\hline$\leq 30$ & 306 & $148(48.4 \%)$ & $158(51.6 \%)$ & & $173(56.5 \%)$ & $133(43.5 \%)$ & \\
\hline$>30$ & 64 & $42(65.6 \%)$ & $22(34.4 \%)$ & & $39(60.9 \%)$ & $25(39.1 \%)$ & \\
\hline $\mathrm{RD}(\mathrm{cm})$ & & & & 0.372 & & & 0.909 \\
\hline$\leq 1$ & 205 & $101(49.3 \%)$ & $104(50.7 \%)$ & & $118(57.6 \%)$ & $87(42.4 \%)$ & \\
\hline$>1$ & 165 & $\begin{array}{l}89(53.9 \%) \\
8\end{array}$ & $76(46.1 \%)$ & & $94(57 \%)$ & $71(43 \%)$ & \\
\hline Surgical procedure $(\mathrm{min})$ & & & & 0.071 & & & 0.536 \\
\hline$\leq 240$ & 305 & $150(49.2 \%)$ & $155(50.8 \%)$ & & $177(58.0 \%)$ & $128(42.0 \%)$ & \\
\hline$>240$ & 65 & $40(61.5 \%)$ & $25(38.5 \%)$ & & $35(53.8 \%)$ & $30(46.2 \%)$ & \\
\hline Blood loss during PDS (ml) & & & & 0.361 & & & 0.051 \\
\hline$<1000$ & 336 & $170(50.6 \%)$ & $166(49.4 \%)$ & & $198(58.9 \%)$ & $138(41.1 \%)$ & \\
\hline$>1000$ & 34 & $20(58.8 \%)$ & $14(41.2 \%)$ & & $14(41.2 \%)$ & $20(58.8 \%)$ & \\
\hline Bbod transfusion & & & & 0.001 & & & 0.84 \\
\hline No & 122 & $48(39.3 \%)$ & $74(60.7 \%)$ & & $69(56.6 \%)$ & $53(43.4 \%)$ & \\
\hline Yes & 248 & $142(57.3 \%)$ & $106(42.7 \%)$ & & $143(57.7 \%)$ & $105(42.3 \%)$ & \\
\hline Plsma transfusion & & & & $<0.001$ & & & 0.37 \\
\hline No & 294 & $137(46.6 \%)$ & $157(53.4 \%)$ & & $165(56.1 \%)$ & $129(43.9 \%)$ & \\
\hline Yes & 76 & $53(69.7 \%)$ & $23(30.3 \%)$ & & $47(61.8 \%)$ & $29(38.2 \%)$ & \\
\hline $\begin{array}{l}\text { Regimen of adjuvant chemotherapy } \\
\text { Regite }\end{array}$ & & & & 0.286 & & & 0.059 \\
\hline Docetaxel/Paclitaxel plus cisp batin & 123 & $68(55.3 \%)$ & $55(44.7 \%)$ & & $62(50.4 \%)$ & $61(49.6 \%)$ & \\
\hline Docetaxel/Paclitaxel plus carboplatin & 247 & $122(49.4 \%)$ & $125(50.6 \%)$ & & $150(60.7 \%)$ & $97(39.3 \%)$ & \\
\hline Cycle of adjuvant chemotherapy* & & & & 0.826 & & & 0.136 \\
\hline$<6$ & 56 & $28(50 \%)$ & $28(50 \%)$ & & $27(48.2 \%)$ & $29(51.8 \%)$ & \\
\hline$\geq 6$ & 314 & $162(51.6 \%)$ & $152(48.4 \%)$ & & $185(58.9 \%)$ & $129(41.1 \%)$ & \\
\hline Second debulking surgery & & & & 0.361 & & & 0.654 \\
\hline No & 299 & $157(52.5 \%)$ & $142(47.5 \%)$ & & $173(57.9 \%)$ & $126(42.1 \%)$ & \\
\hline Yes & 71 & $33(46.5 \%)$ & $38(53.5 \%)$ & & $39(54.9 \%)$ & $32(45.1 \%)$ & \\
\hline
\end{tabular}


Fig. 2. NLR predicted PFS and OS (A and B); PC predicted PFS and OS (C and D).

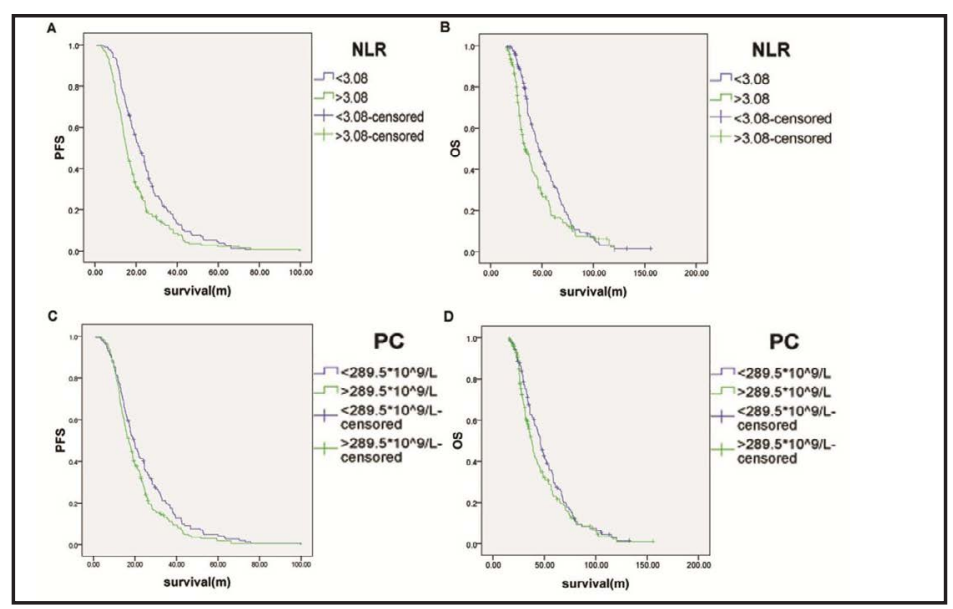

Table 3. NLR and PC predicted PFS and OS. *Grade 1 referred to the well-differentiated epithelial ovarian cancer; Grade 2 referred to the moderately-differentiated epithelial ovarian cancer; Grade 3 referred to the poorly-differentiated epithelial ovarian cancer. Abbreviations: NLR, neutrophil-to-lymphocyte ratio; PC, platelet count; PFS, progression free survival; OS, overall survival; HR, hazard ratio; RD, residual disease; PDS, primary debulking surgery

\begin{tabular}{|c|c|c|c|c|c|c|c|}
\hline & No. of patients & Univariate analysis, $\mathrm{P}$ & $\begin{array}{c}\text { PFS } \\
\text { Multivariate analysis, } \mathrm{P}\end{array}$ & HR(95\%Cl) & Univariate analysis, $\mathrm{P}$ & $\begin{array}{c}\text { OS } \\
\text { Multivariate analysis, } \mathrm{P}\end{array}$ & $\mathrm{HR}(95 \% \mathrm{Cl})$ \\
\hline $\begin{array}{c}\substack{\mathrm{Age}(\mathrm{y}) \\
<65 \\
\geq 65} \\
\end{array}$ & $\begin{array}{l}315 \\
55\end{array}$ & $\begin{array}{c}\text { Referent } \\
0.797\end{array}$ & & & $\begin{array}{l}\text { Referent } \\
0.561\end{array}$ & & \\
\hline $\begin{array}{c}\text { Menopause } \\
\text { No }\end{array}$ & 145 & Referent & Referent & & Referent & & \\
\hline $\begin{array}{l}\text { Yes } \\
\text { Pre-perative ascites volume }(\mathrm{ml}) \\
<1000\end{array}$ & & Referent & Referent & & Referent & & \\
\hline $\begin{array}{l}<1000 \\
1000-3000 \\
>3000\end{array}$ & $\begin{array}{l}153 \\
127 \\
90\end{array}$ & $\begin{array}{l}\text { Reterent } \\
0.001 \\
0.014\end{array}$ & $\begin{array}{c}\text { Referent } \\
0.128\end{array}$ & & $\begin{array}{l}\text { Referent } \\
0.002\end{array}$ & 0.132 & \\
\hline $\begin{array}{c}\text { Pre-operative CA125 value }(\mathrm{U} / \mathrm{ml}) \\
<1000\end{array}$ & 269 & Referent & & & Referent & & \\
\hline $\begin{array}{l}1000-5000 \\
>5000\end{array}$ & $\begin{array}{l}86 \\
15\end{array}$ & $\begin{array}{l}0.145 \\
0.306\end{array}$ & & & $\begin{array}{l}0.176 \\
0.684\end{array}$ & & \\
\hline $\begin{array}{l}\text { Histology } \\
\text { Serous }\end{array}$ & 238 & 0.500 & & & Peferent & & \\
\hline $\begin{array}{l}\text { Serous } \\
\text { Endometriod }\end{array}$ & $\begin{array}{l}238 \\
46\end{array}$ & $\begin{array}{c}\text { Referent } \\
0.086\end{array}$ & $\begin{array}{c}\text { Referent } \\
0.017\end{array}$ & $0.67(0.48-0.93)$ & $\begin{array}{c}\text { Referent } \\
0.146\end{array}$ & $\begin{array}{c}\text { Referent } \\
0.041\end{array}$ & $0.69(0.48-0.99)$ \\
\hline $\begin{array}{l}\text { Mucinous } \\
\text { Clear cell }\end{array}$ & $\begin{array}{c}3 \\
11\end{array}$ & & & $\begin{array}{l}29.418(8.533-101.45) \\
1.63(0.60-4.45)\end{array}$ & $\begin{array}{l}0.009 \\
0.958\end{array}$ & $\begin{array}{l}0.017 \\
0.584\end{array}$ & $5.73(1.36-24.09)$ \\
\hline Adenocarcinoma, not otherwise specified & 72 & $\begin{array}{l}0.901 \\
0.098\end{array}$ & & $1.13(0.87-1.49)$ & 0.074 & 0.189 & $\begin{array}{l}1.38(0.44-4.399) \\
1.21(0.91-62)\end{array}$ \\
\hline $\begin{array}{l}\text { Grade of tumor" } \\
\text { G1 } \\
\text { G2 } \\
\text { G3 }\end{array}$ & $\begin{array}{r}24 \\
133\end{array}$ & $\begin{array}{l}\text { Referent } \\
<0.001\end{array}$ & $\begin{array}{c}\text { Referent } \\
<0.001\end{array}$ & $2.65(1.66-4.23)$ & $\begin{array}{l}\text { Referent } \\
<0.001\end{array}$ & $\begin{array}{c}\text { Referent } \\
0.002\end{array}$ & $2.42(1.40-4.18)$ \\
\hline Stay in hospital (d) & & Referent & Referent & $3.00(1.89-4.75)$ & $<0.001$ & & $2.69(1.56-4.65)$ \\
\hline $\begin{array}{l}\leq 30 \\
>30 \\
>30\end{array}$ & $\begin{array}{l}306 \\
64\end{array}$ & $\begin{array}{l}\text { Referent } \\
0.074\end{array}$ & $\begin{array}{l}\text { Referent } \\
0.664\end{array}$ & & $\begin{array}{c}\text { Referent } \\
0.155\end{array}$ & & \\
\hline $\begin{array}{c}\mathrm{RD}(\mathrm{cm}) \\
\leq 1\end{array}$ & 205 & Referent & Referent & 2006165265 & Referent & Referent & $17361362=1$ \\
\hline $\begin{array}{l}>1 \\
\text { Surgical procedure }(\min )\end{array}$ & 165 & $<0.001$ & $<0.001$ & $2.09(1.65-2.65)$ & & & $1.73(1.36-2.21)$ \\
\hline $\begin{array}{l}\leq 240 \\
>240\end{array}$ & $\begin{array}{l}305 \\
65\end{array}$ & $\begin{array}{l}\text { Referent } \\
0.499\end{array}$ & & & $\begin{array}{l}\text { Referent } \\
0.480\end{array}$ & & \\
\hline $\begin{array}{l}\text { Blood loss during PDS (ml) } \\
<1000 \\
>1000\end{array}$ & $\begin{array}{l}336 \\
34\end{array}$ & $\begin{array}{c}\text { Referent } \\
0.884\end{array}$ & & & $\begin{array}{l}\text { Referent } \\
0.967\end{array}$ & & \\
\hline $\begin{array}{l}\text { Blood transfusion } \\
\text { No }\end{array}$ & 122 & Referent & & & Referent & Referent & \\
\hline $\begin{array}{l}\text { Yes } \\
\text { Plasma transfusion }\end{array}$ & 248 & 0.115 & & & 0.013 & 0.903 & \\
\hline $\begin{array}{l}\text { No } \\
\text { Yes }\end{array}$ & 294 & $\begin{array}{c}\text { Referent } \\
0.102\end{array}$ & & & $\begin{array}{l}\text { Referent } \\
0.141\end{array}$ & & \\
\hline $\begin{array}{l}\text { Regimen of addiuvant chemotherapy } \\
\text { Docetaxel/Paclitaxel plus cisplatin } \\
\text { Docetaxel/Paclitaxel plus carboplatin }\end{array}$ & $\begin{array}{l}123 \\
247\end{array}$ & $\begin{array}{l}\text { Referent } \\
0.002\end{array}$ & $\begin{array}{c}\text { Referent } \\
0.050\end{array}$ & $0.79(0.63-1.00)$ & $\begin{array}{c}\text { Referent } \\
0.041\end{array}$ & $\begin{array}{c}\text { Referent } \\
0.858\end{array}$ & \\
\hline $\begin{array}{l}\text { Cycle of adjuvant chemotherapy } \\
<6 \\
\geq 6\end{array}$ & $\begin{array}{c}56 \\
314\end{array}$ & $\begin{array}{c}\text { Referent } \\
0.637\end{array}$ & & & $\begin{array}{l}\text { Referent } \\
0.033\end{array}$ & $\begin{array}{c}\text { Referent } \\
0.021\end{array}$ & $0.66(0.46-0.94)$ \\
\hline $\begin{array}{l}\text { Second debulking surgery } \\
\text { No }\end{array}$ & $\begin{array}{l}299 \\
71\end{array}$ & $\begin{array}{l}\text { Referent } \\
0.053\end{array}$ & $\begin{array}{l}\text { Referent } \\
0.164\end{array}$ & & $\begin{array}{l}\text { Referent } \\
0.033\end{array}$ & $\begin{array}{l}\text { Referent } \\
0.228\end{array}$ & \\
\hline $\begin{array}{c}\text { NLR } \\
\substack{\text { Les.08 } \\
>3.08}\end{array}$ & $\begin{array}{l}180 \\
190\end{array}$ & $\begin{array}{c}\text { Referent } \\
0.022\end{array}$ & $\begin{array}{c}\text { Referent } \\
0.005\end{array}$ & $1.38(1.10-1.72)$ & $\begin{array}{l}\text { Referent } \\
0.001\end{array}$ & $\begin{array}{c}\text { Referent } \\
0.010\end{array}$ & $1.38(1.08-1.77)$ \\
\hline $\begin{array}{l}\mathrm{PC} \\
<289.5^{*} 109 / \mathrm{L}\end{array}$ & 158 & Referent & Referent & 5301060160 & Referent & Referent & 123009615 \\
\hline
\end{tabular}

than that of patients with NLR $<3.08$ (33.5 months vs. 46.8 months, HR 1.3, 95\% CI 1.01$1.66, P=0.001)$. The median OS of patients with $\mathrm{PC}>289.5^{*} 10^{9} / \mathrm{L}$ was shorter than that of patients with $\mathrm{PC}<289.5^{*} 10^{9} / \mathrm{L}$, but the difference was not significant (37.3 months vs. 46.1 months, HR 1.14, 95\% CI 0.89-1.46, $P=0.306$ ) (Fig. 2 and Table 3).

Peripheral blood index value by combined NLR and PC

The PBIV of each patient was calculated. The optimal cut-off value of PBIV predicting OS was 0.5 (AUC 0.66, $P<0.001$, sensitivity 0.38 , specificity 0.87 ) (Fig. 3A).

The median PFS of patients with PBIV $>0.5$ was 7.9 months shorter than that of patients with PBIV $<0.5$ (16.2 months vs. 24.1 months, $P=0.002$ ) (Fig. 3B). The median OS of patients with PBIV $>0.5$ was 14.0 months shorter than that of patients with PBIV $<0.5(37.3$ months vs. 51.3 months, $P=0.011$ ) (Fig. 3C). 
Subgroup analyses for serous and non-serous EOC patients

For serous EOC patients, the median PFS of patients with NLR $>3.08$ was 6.7 months shorter than that of patients with NLR $<3.08$ (15.6 months vs. 22.3 months, $P=0.001$ ) (Fig. $4 \mathrm{~A}$ ). The median OS of patients with NLR $>3.08$ was 13.7 months shorter than that of patients with NLR $<3.08$ (34.9 months vs. 48.6 months, $P=0.002$ ) (Fig. 4B). The median PFS of patients with PC $>289.5^{*} 10^{9} / \mathrm{L}$ was 2.2 months shorter than that of patients with PC $<289.5^{*} 10^{9} / \mathrm{L}$, but the difference was not significant (17.9 months vs. 20.1 months, $P=$ 0.156 ) (Fig. 4C). The median OS of patients with PC $>289.5^{*} 10^{9} / \mathrm{L}$ was 9.5 months shorter than that of patients with PC $<289.5^{*} 10^{9} / \mathrm{L}$, but the difference was not significant (38.2 months vs. 47.7 months, $P=0.126$ ) (Fig. 4D).

For non-serous EOC patients, the median PFS of patients with NLR $>3.08$ was 5.4 months shorter than that of patients with NLR $<3.08$ (14.9 months vs. 20.3 months, $P=0.045$ ) (Fig. $5 \mathrm{~A}$ ). The median OS of patients with NLR >3.08 was 11.7 months shorter than that of patients with NLR $<3.08$, but the difference was not significant $(33.5$ months vs. 45.2 months, $P=0.154$ ) (Fig. 5B). The median PFS of patients with PC $>289.5^{*} 10^{9} / \mathrm{L}$ was 1.9 months shorter than that of patients with PC $<289.5^{*} 10^{9} / \mathrm{L}(15.8$ months vs. 17.7 months, $P=$ 0.048 ) (Fig. 5C). The median OS of patients with PC $>289.5^{*} 10^{9} / \mathrm{L}$ was 6.1 months shorter than that of patients with $\mathrm{PC}<289.5^{*} 10^{9} / \mathrm{L}$, but the difference was not significant (36.8 months vs. 42.9 months, $P$ $=0.390$ ) (Fig. 5D).

\section{Discussion and Conclusion}

The results of our retrospective study suggested that H-NLR and H-PC could predict poor long-term outcome of patients with FIGO stage III EOC who live in Northeast China. The median PFS and OS of the patients with H-NLR and $\mathrm{H}-\mathrm{PC}$ were significantly shorter than those of patients with L-NLR and L-PC. We identified the optimal cut-off values of 3.08 for NLR and $289.5^{*} 10^{9} / \mathrm{L}$ for PC.

Moreover, H-NLR was associated with earlier onset age, more preoperative ascites, higher preoperative CA125 value, lower differentiation of tumor, and longer period of

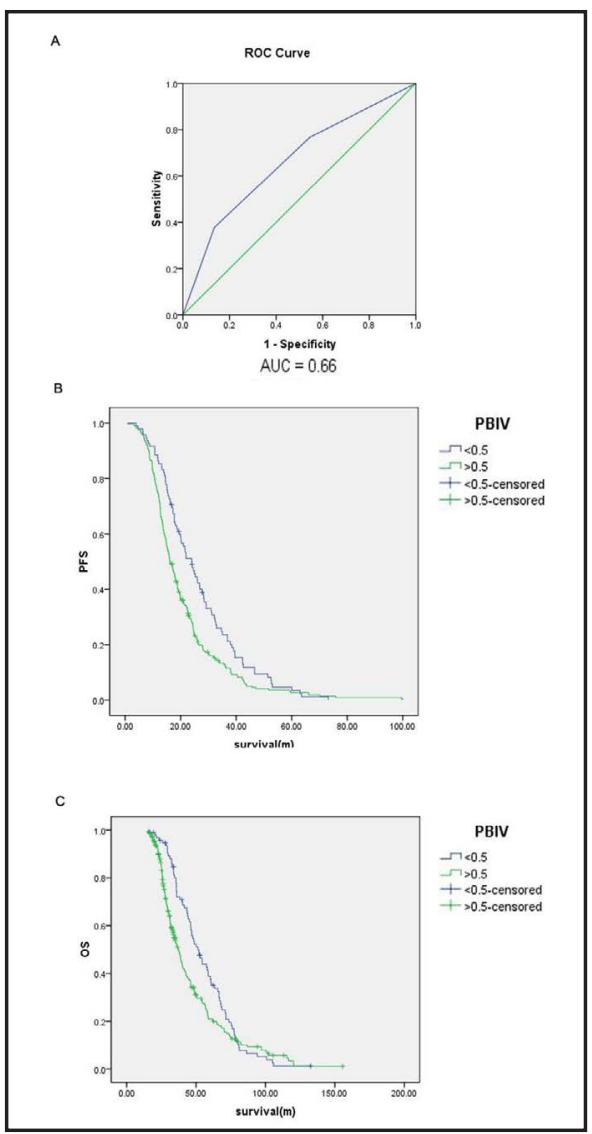

Fig. 3. ROC curves of PBIV model as predictor of OS (A); PBIV model predicted PFS (B); PBIV model predicted OS (C).

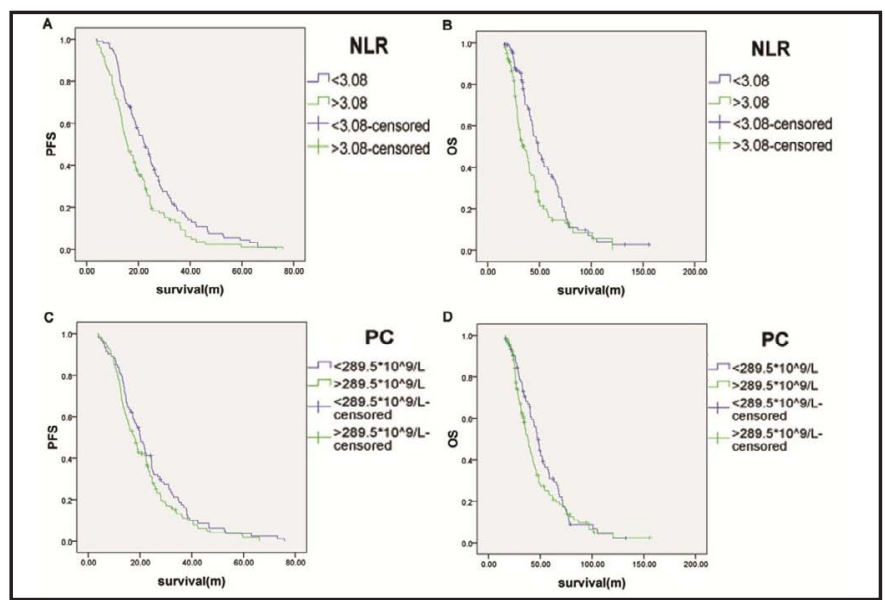

Fig. 4. NLR predicted PFS and OS of serous EOC patients (A and B); PC predicted PFS and OS of serous EOC patients (C and D). 
stay in hospital, whereas H-PC was associated with more preoperative ascites and higher preoperative CA125 value. Consistent with our results, other papers reported that the elevated NLR and PC were corresponding to the elevated preoperative CA125 value [15, 16].

Recently published papers demonstrated that gastric cancer, esophageal cancer, myeloma, small cell lung cancer, and non-small cell lung cancer patients with H-NLR and H-PC showed poor OS[5-8, 17]. Six Chinese institutes have

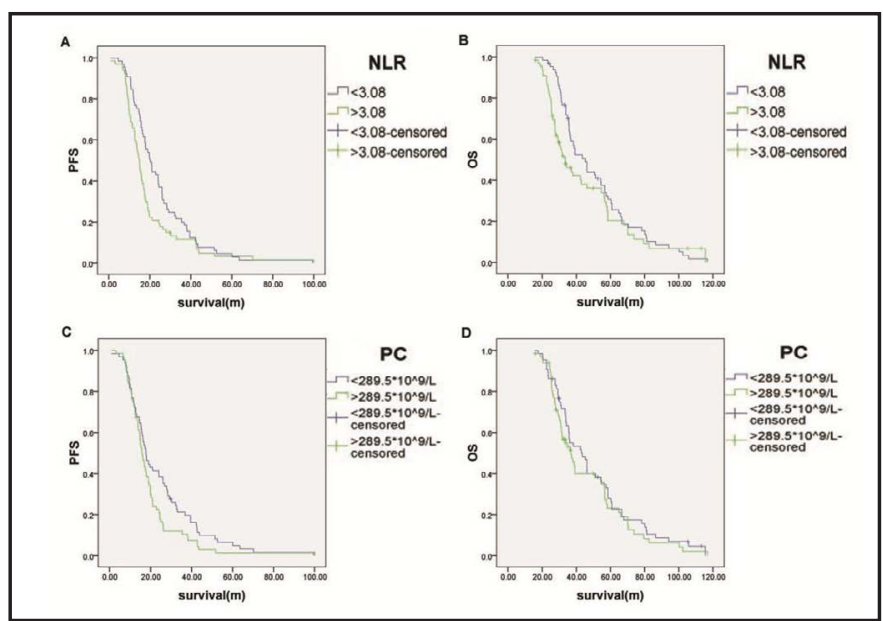

Fig. 5. NLR predicted PFS and OS of non-serous EOC patients (A and B); PC predicted PFS and OS of non-serous EOC patients (C and D). investigated and indicated the correlation between NLR and long-term outcome of EOC [12][18-22]. Most studies included only about 100 patients. Compared with these studies, we specifically analyzed the data of FIGO stage IIIC EOC patients, which avoided heterogeneity caused by tumor stage. Moreover, among these six studies, five studies were sponsored by the institutes in South China [18-22]. Only one retrospective study analyzing the data of 80 FIGO stage III-IV ovarian cancer patients was sponsored by an institute in North China [12]. The results suggested that H-NLR was associated with poor prognosis. Our study is the first to provide data for patients from Northeast China with advanced EOC. Other published studies analyzing the data of foreign patients outside China had the consistent conclusion with us [4, 15, 16, 23-25].

Patients with H-PC were characterized as having thrombocytosis. H-PC was correlated with the OS of TNM stage IV colorectal cancer [26]. Watrowski R, et al. retrospectively analyzed 172 malignant and 584 benign primary adnexal tumors and indicated that H-PC predicted malignancy [27]. Several papers suggested that thrombocytosis was associated with poor prognosis of EOC patients, which was the logical consequence of the role of platelets in the pathogenesis of ovarian cancer [28-32]. However, the number of patients involved in the published papers was insufficient. Moreover, subgroup analysis of advanced EOC patients was limited. Our study was the first to investigate the relationship between $\mathrm{H}-\mathrm{PC}$ and prognosis for the patients from Northeast China with advanced EOC.

Tumor-associated neutrophils have been demonstrated in the cancer microenvironment. Neutrophils play important roles in tumor progression, angiogenesis, and invasion [33], and a lack of tumor-infiltrating lymphocytes is associated with poor prognosis of ovarian cancer $[34,35]$. These results further support our finding that EOC patients with H-NLR had poor long-term outcome.

Our study had some strengths. First, all 370 patients involved were diagnosed with FIGO stage IIIC EOC, which eliminated bias due to stage. Second, the median follow-up period of this study exceeded 10 years. Third, NLR and PC are both easily available biomarkers. Moreover, $\mathrm{PC}$ is a better variable than platelet-to-lymphocyte ratio as it eliminates bias due to different lymphocyte counts. However, this study still has some limitations. As this was a mono-institutional study, a multi-institutional study investigating the predictive effect of NLR and PC in advanced EOC is needed. Moreover, this retrospective study depended on accurate documentation and a prospective study without recall bias should be performed.

In conclusion, H-NLR and H-PC could predict poor long-term outcome of patients with FIGO stage III EOC. 


\section{Cellular Physiology Cell Physiol Biochem 2018;46:178-186 \begin{tabular}{ll|l} 
and Biochemistry Published online: March 26, 2018 & $\begin{array}{l}\text { C) } 2018 \text { The Author(s). Published by S. Karger AG, Basel } \\
\text { www.karger.com/cpb }\end{array}$ \\
\hline
\end{tabular}}

Zhou et al.: NLR and PC Predict the Outcome of IIIC EOC

\section{Disclosure Statement}

No conflict of interests exists.

\section{References}

1 Siegel RL, Miller KD, Jemal A: Cancer Statistics, 2017 CA Cancer J Clin 2017;67:7-30.

-2 Chen W, Zheng R, Baade PD, Zhang S, Zeng H, Bray F, Jemal A, Yu XQ, He J: Cancer statistics in China, 2015 CA Cancer J Clin 2016;66:115-132.

-3 Rauh-Hain JA, Diver EJ, Clemmer JT, Bradford LS, Clark RM, Growdon WB, Goodman AK, Boruta DM, 2nd, Schorge JO, del Carmen MG: Carcinosarcoma of the ovary compared to papillary serous ovarian carcinoma: a SEER analysis. Gynecol Oncol 2013;131:46-51.

4 Polat M, Senol T, Ozkaya E, Ogurlu Pakay G, Cikman MS, Konukcu B, Ozten MA, Karateke A: Neutrophil to lymphocyte and platelet to lymphocyte ratios increase in ovarian tumors in the presence of frank stromal invasion. Clin Transl Oncol 2016;18:457-463.

5 Ishizuka M, Oyama Y, Abe A, Kubota K: Combination of platelet count and neutrophil to lymphocyte ratio is a useful predictor of postoperative survival in patients undergoing surgery for gastric cancer. J Surg Oncol 2014;110:935-941.

6 Kasmann L, Bolm L, Schild SE, Janssen S, Rades D: Neutrophil-to-Lymphocyte Ratio Predicts Outcome in Limited Disease Small-cell Lung Cancer. Lung 2017;195:217-224.

7 McLaren PJ, Bronson NW, Hart KD, Vaccaro GM, Gatter KM, Thomas CR, Jr., Hunter JG, Dolan JP: Neutrophilto-Lymphocyte and Platelet-to-Lymphocyte Ratios can Predict Treatment Response to Neoadjuvant Therapy in Esophageal Cancer. J Gastrointest Surg 2017;21:607-613.

8 Gao Y, Zhang H, Li Y, Wang D, Ma Y, Chen Q: Preoperative pulmonary function correlates with systemic inflammatory response and prognosis in patients with non-small cell lung cancer: results of a singleinstitution retrospective study. Oncotarget 2017;8:27489-27501.

$>9$ Zhou Q Hong L, Zuo MZ, He Z: Prognostic significance of neutrophil to lymphocyte ratio in ovarian cancer: evidence from 4, 910 patients. Oncotarget 2017;8:68938-68949.

10 Chen S, Zhang L, Yan G, Cheng S, Fathy AH, Yan N, Zhao Y: Neutrophil-to-Lymphocyte Ratio Is a Potential Prognostic Biomarker in Patients with Ovarian Cancer: A Meta-Analysis. Biomed Res Int 2017;2017:7943467.

11 Shi Y, Ye D, Lu W, Zhao C, Xu J, Chen L: Histological classification in 10288 cases of ovarian malignant tumors in China. Zhonghua Fu Chan Ke Za Zhi 2002;37:97-100.

12 Zhang WQ, Hao Q: Preoperative blood neutrophil to lymphocyte ratio as an independent prognostic predictor for epithelial ovarian cancer. Chin J Clin Oncol 2014;41:634-638.

13 Prat J: Staging classification for cancer of the ovary, fallopian tube, and peritoneum. Int J Gynaecol Obstet 2014;124:1-5.

14 Hu ZD, Zhou ZR, Qian S: How to analyze tumor stage data in clinical research. J Thorac Dis 2015;7:566-575.

15 Williams KA, Labidi-Galy SI, Terry KL, Vitonis AF, Welch WR, Goodman A, Cramer DW: Prognostic significance and predictors of the neutrophil-to-lymphocyte ratio in ovarian cancer. Gynecol Oncol 2014;132:542-50.

16 Cho H, Hur HW, Kim SW, Kim SH, Kim JH, Kim YT, Lee K: Pre-treatment neutrophil to lymphocyte ratio is elevated in epithelial ovarian cancer and predicts survival after treatment. Cancer Immunol Immunother 2009;58:15-23.

17 Shi L, Qin X, Wang H, Xia Y, Li Y, Chen X, Shang L, Tai YT, Feng X, Acharya P, Acharya C, Xu Y, Deng S, Hao M, Zou D, Zhao Y, Ru K, Qiu L, An G: Elevated neutrophil-to-lymphocyte ratio and monocyte-to-lymphocyte ratio and decreased platelet-to-lymphocyte ratio are associated with poor prognosis in multiple myeloma. Oncotarget 2017;8:18792-18801.

18 Feng Z, Wen H, Bi R, Ju X, Chen X, Yang W, Wu X: Preoperative neutrophil-to-lymphocyte ratio as a predictive and prognostic factor for high-grade serous ovarian cancer. PLoS One 2016;11:e0156101.

19 Zhang WW, Liu KJ, Hu GL, Liang WJ: Preoperative platelet/lymphocyte ratio is a superior prognostic factor compared to other systemic inflammatory response markers in ovarian cancer patients. Tumour Biol 2015;36:8831-8837. 


\section{Cellular Physiology Cell Physiol Biochem 2018;46:178-186

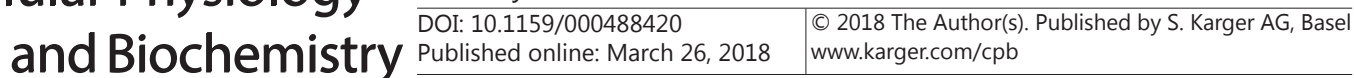

Zhou et al.: NLR and PC Predict the Outcome of IIIC EOC

20 Wang YQ Jin C, Zheng HM, Zhou K, Shi BB, Zhang Q, Zheng FY, Lin F: A novel prognostic inflammation score predicts outcomes in patients with ovarian cancer. Clin Chim Acta 2016;456:163-169.

21 Wang Y, Liu P, Xu Y, Zhang W, Tong L, Guo Z, Ni H: Preoperative neutrophil-to-lymphocyte ratio predicts response to first-line platinum-based chemotherapy and prognosis in serous ovarian cancer. Cancer Chemother Pharmacol 2015;75:255-262.

22 Miao Y, Yan Q, Li S, Li B, Feng Y: Neutrophil to lymphocyte ratio and platelet to lymphocyte ratio are predictive of chemotherapeutic response and prognosis in epithelial ovarian cancer patients treated with platinum-based chemotherapy. Cancer Biomark 2016;17:33-40.

23 Ashrafganjoei T, Mohamadianamiri M, Farzaneh F, Hosseini MS, Arab M: Investigating preoperative hematologic markers for prediction of ovarian cancer surgical outcome. Asian Pac J Cancer Prev 2016;17:1445-1448.

24 Topcu HO, Guzel AI, Ozer I, Kokanali MK, Gokturk U, Muftuoglu KH, Doganay M: Comparison of neutrophil/ lymphocyte and platelet/ lymphocyte ratios for predicting malignant potential of suspicious ovarian masses in gynecology practice. Asian Pac J Cancer Prev 2014;15:6239-6241.

25 Prodromidou A, Andreakos P, Kazakos C, Vlachos DE, Perrea D, Pergialiotis V: The diagnostic efficacy of platelet-to-lymphocyte ratio and neutrophil-to-lymphocyte ratio in ovarian cancer. Inflamm Res 2017;66:467-475.

-26 Pedrazzani C, Mantovani G, Fernandes E, Bagante F, Luca Salvagno G, Surci N, Campagnaro T, Ruzzenente A, Danese E, Lippi G, Guglielmi A: Assessment of neutrophil-to-lymphocyte ratio, platelet-to-lymphocyte ratio and platelet count as predictors of long-term outcome after R0 resection for colorectal cancer. Sci Rep 2017;7:1494.

-27 Watrowski R, Heinze G, Jager C, Forster J, Zeillinger R: Usefulness of the preoperative platelet count in the diagnosis of adnexal tumors. Tumour Biol 2016;37:12079-12087.

-28 Cozzi GD, Samuel JM, Fromal JT, Keene S, Crispens MA, Khabele D, Beeghly-Fadiel A: Thresholds and timing of pre-operative thrombocytosis and ovarian cancer survival: analysis of laboratory measures from electronic medical records. BMC Cancer 2016;16:612.

29 Menczer J: Preoperative elevated platelet count and thrombocytosis in gynecologic malignancies. Arch Gynecol Obstet 2017;295:9-15.

-30 Feng Z, Wen H, Bi R, Duan Y, Yang W, Wu X: Thrombocytosis and hyperfibrinogenemia are predictive factors of clinical outcomes in high-grade serous ovarian cancer patients. BMC Cancer 2016;16:43.

-31 Li AJ, Madden AC, Cass I, Leuchter RS, Lagasse LD, Karlan BY: The prognostic significance of thrombocytosis in epithelial ovarian carcinoma. Gynecol Oncol 2004;92:211-214.

32 Naina HV, Harris S: Paraneoplastic thrombocytosis in ovarian cancer. N Engl J Med 2012;366:1840.

-33 Powell DR, Huttenlocher A: Neutrophils in the tumor microenvironment. Trends Immunol 2016;37:41-52.

-34 Hwang WT, Adams SF, Tahirovic E, Hagemann IS, Coukos G: Prognostic significance of tumor-infiltrating T cells in ovarian cancer: a meta-analysis. Gynecol Oncol 2012;124:192-198.

-35 Han LY, Fletcher MS, Urbauer DL, Mueller P, Landen CN, Kamat AA, Lin YG, Merritt WM, Spannuth WA, Deavers MT, De Geest K, Gershenson DM, Lutgendorf SK, Ferrone S, Sood AK: HLA class I antigen processing machinery component expression and intratumoral T-Cell infiltrate as independent prognostic markers in ovarian carcinoma. Clin Cancer Res 2008;14:3372-3379. 